\title{
Erratum to: Using otoliths to estimate age and growth of a large Australian endemic monacanthid, Nelusetta ayraudi (Quoy and Gaimard, 1824)
}

\author{
Marcus E. Miller • John Stewart • Ron J. West
}

Published online: 29 June 2010

(C) Springer Science+Business Media B.V. 2010

\section{Erratum to: Environ Biol Fish \\ DOI 10.1007/s10641-010-9639-4}

Unfortunately, there was a mistake in the article title. "Using otoliths to estimate age and growth of a large Australian endemic monocanthid, (Quoy and Gaimard, 1824)" should be "Using otoliths to estimate age and growth of a large Australian endemic monacanthid, (Quoy and Gaimard, 1824)" with the word "monocanthid" changed to "monacanthid".

The online version of the original article can be found at http:// dx.doi.org/10.1007/s10641-010-9639-4.

M. E. Miller $(\bowtie) \cdot$ J. Stewart

NSW Department of Primary Industries, Cronulla Fisheries

Research Centre of Excellence,

PO Box 21, Cronulla, NSW 2230, Australia

e-mail: marcus.miller@dpi.nsw.gov.au

R. J. West

ANCORS, University of Wollongong,

Wollongong, NSW 2522, Australia 